Article

\title{
Environmental Risk Mitigation by Biodiesel Blending from Eichhornia crassipes: Performance and Emission Assessment
}

\author{
Hasanain A. Abdul Wahhab ${ }^{1}$ and Hussain H. Al-Kayiem ${ }^{2, * \text { D }}$ \\ 1 Mechanical Engineering Department, University of Technology, Baghdad 10081, Iraq; \\ 20085@uotechnology.edu.iq \\ 2 Mechanical Engineering Department, Universiti Teknologi PETRONAS, Seri Iskandar 32610, Malaysia \\ * Correspondence: hussain_kayiem@utp.edu.my
}

Citation: Abdul Wahhab, H.A.; Al-Kayiem, H.H. Environmental Risk Mitigation by Biodiesel Blending from Eichhornia crassipes: Performance and Emission Assessment. Sustainability 2021, 13, 8274. https:// doi.org/10.3390/su13158274

Academic Editors: Lucian-Ionel Cioca and Elena Rada

Received: 1 July 2021

Accepted: 21 July 2021

Published: 24 July 2021

Publisher's Note: MDPI stays neutral with regard to jurisdictional claims in published maps and institutional affiliations.

Copyright: (c) 2021 by the authors. Licensee MDPI, Basel, Switzerland. This article is an open access article distributed under the terms and conditions of the Creative Commons Attribution (CC BY) license (https:// creativecommons.org/licenses/by/ $4.0 /)$.

\begin{abstract}
The aggressive growth of Eichhornia crassipes (Water Hyacinth) plants causes severe damage to the irrigation, environment, and waterway systems in Iraq. This study aims to produce, characterize, and test biofuel extracted from the Eichhornia crassipes plant in Iraq. The extracted biodiesel was mixed at $10 \%, 20 \%$, and $40 \%$ with neat diesel to produce three biodiesel samples. The methodology consists of the physiochemical properties of the samples that were characterized. The performance of the IC engine fueled by neat and biodiesel samples was measured under various operational conditions. The exhaust gases were analyzed to estimate the compounds to assess the environmental impact. The results showed that the density and viscosity of mixtures increase and the calorific value decrease with biodiesel. The engine test showed that the diesel $+10 \mathrm{BE}$, diesel $+20 \mathrm{BE}$, and diesel $+40 \mathrm{BE}$ enhanced brake thermal efficiency using $2.6 \%, 4.2 \%$, and $6.3 \%$, respectively, compared to neat diesel. Exhaust tests show a slight reduction, of $0.85-3.69 \%$ and $2.48-6.93 \%$, in CO and HC emission, respectively. NOx is higher by $1.87-7.83 \%$ compared with neat diesel. The results revealed that biodiesel blended from Eichhornia crassipes is a viable solution to mitigate the drastic impact on the environment and economy in Iraq. The blended biodiesel has good potential to be mixed with the locally produced diesel from oil refineries.
\end{abstract}

Keywords: biofuel; Eichhornia crassipes; emission of biodiesel; fuel technology; water hyacinth plant; waste to wealth

\section{Introduction}

\subsection{Background and Research Literature}

Oil and natural gases, which are depleting resources, represent the main economic pillar of Iraq and the main source of energy for power production and transportation. Meanwhile, emissions caused by combustion have considerably increased environmental pollution in the country [1]. In the last few years, scientists in Iraq have directed their interests in discovering alternatives to fossil fuels. One of these alternatives is vegetable oils to produce biofuels as renewable energy, which is environmentally friendly, renewable, and biodegradable [2,3]. Biodiesel is a better lubricant than diesel oil that lengthens engine life. Several vegetable oils, such as castor, sunflower, and palm trees, are available in Iraq. However, all these vegetable oils have high values and important uses other than biodiesel production. A certain raw material must be readily available during selection. Also, it must not be useful for another purpose rather than being used for biodiesel production. Hirkude and Padalkar [4] have reported waste-fried oil methyl ester blend and [5] reported biodiesel production from used cooking oil. Benjumea et al. [6,7] characterized and reported biodiesel blended from palm oil. In contrast, the authors of [8] have reported their experimental result about a diesel engine's performance and emission assessment fueled with methyl chloroformates of a rubber seed oil.

Eichhornia crassipes (E. crassipes), also named Water Hyacinth, has been a source of interest in recent studies to blend and characterize biodiesel. In their review article, the 
authors of [9] shows that E. crassipes, with its low percentage of lignin content, is an attractive biomass source for the biofuel industry. On the other hand, [10] reported lastly that metal-contaminated E. crassipes is viable to produce bioethanol, while another study by [11] reported that the ethanol-generating capacity from E. crassipes was quite comparable to that obtained from other agricultural waste.

Khan et al. [12] extracted bioethanol from the E. crassipes plant and carried out experiments to understand the potential of this biofuel using a single-cylinder diesel engine of $3.5 \mathrm{~kW}$. The experimental results revealed that $10 \%$ blend $(90 \%$ petrol-diesel and $10 \%$ bioethanol) stands out in terms of engine parameters such as enhanced brake power and appreciable brake thermal efficiency. In addition, the emission levels, such as $\mathrm{CO}$ and unburned HC, were comparatively lesser than other blends except for NOx, which eventually depends on the engine construction.

Two studies carried out by a group of researchers in India reported their findings on blended biodiesel from E. crassipes mixed with neat diesel. Venu et al. [13,14] examined the feasibility of fueling biodiesel blended from E. crassipes in a compression engine as a potential alternative energy source. The feedstock to produce the biodiesel is sourced from Pondicherry district, Tamil Nadu, India. They tested neat diesel and mixture samples of $10 \%, 20 \%, 30 \%, 40 \%$, and $100 \%$ volumes of biodiesel mixture. They concluded that the engine's thermal efficiency is improved while $\mathrm{HC}$ and $\mathrm{CO}$ emissions are reduced. However, added blends resulted in slightly higher levels of $\mathrm{CO}_{2}$ and NOx emissions.

Two review articles on the E. crassipes have been published in 2020, one by [9] and another by [15]. The first article discusses the potential of E. crassipes in various applications, not only biofuel extraction. The second article reviewed the previous works on the extraction procedures, characterization, engine fueling performance, and environmental consequences of mixing the blended biofuel with diesel. Both articles are worthy of being visited.

\subsection{Eichhornia Crassipes (Water Hyacinth) in Iraq}

The presence of $E$. Crassipes in water bathmats slows down water flow and leads to sludging. Reduced water flow adversely affects irrigation systems. Investigations demonstrated that this water plant causes considerable loss of water resources through evapotranspiration.

The E. crassipes is an aquatic plant that can tolerate a wide range of habitat conditions (e.g., winds, temperature, $\mathrm{pH}$, salinity, current, and drought), as shown by $[16,17]$. It grows in fresh water at an optimal $\mathrm{pH} 7.0$, a phosphorus concentration of $20 \mathrm{ppm}$, and adequate nitrogen. It can also survive up to 13 days in seawater and has features that make it well adapted for long-distance dispersal and the successful colonization of diverse habitats. The E. crassipes reduce the effective capacity of water reservoirs by up to $400 \mathrm{~m}^{3}$ of water per hectare. A dry climate, such as that in Iraq, causes water levels in reservoirs to fall quickly, thereby causing a major impact on the hydroelectric structures of water reservoirs and streams. Traveling using boats becomes difficult or impossible because of E. crassipes, thereby resulting in water transport problems.

In recent years, rivers and irrigation water streams in Iraq have been suffering from the rapid and wide growth of E. crassipes plants because it inhibits water flow in the Tigris and Euphrates rivers and their tributaries in the provinces of Wasit and Dhi-Qar. Figure 1 shows the distribution of the E. crassipes plant in the rivers of Iraq. The quantitative statistics of the water hyacinth plant extracted by the Directorate of Aquatic Treatment indicate that the quantities increased from $350 \mathrm{sq}$. km in 2006 to $860 \mathrm{sq} . \mathrm{km}$ in 2016 in the southern part of Iraq. This condition led the authorities in charge of water resources to pay high costs to remove these plants from the rivers without benefiting them. 


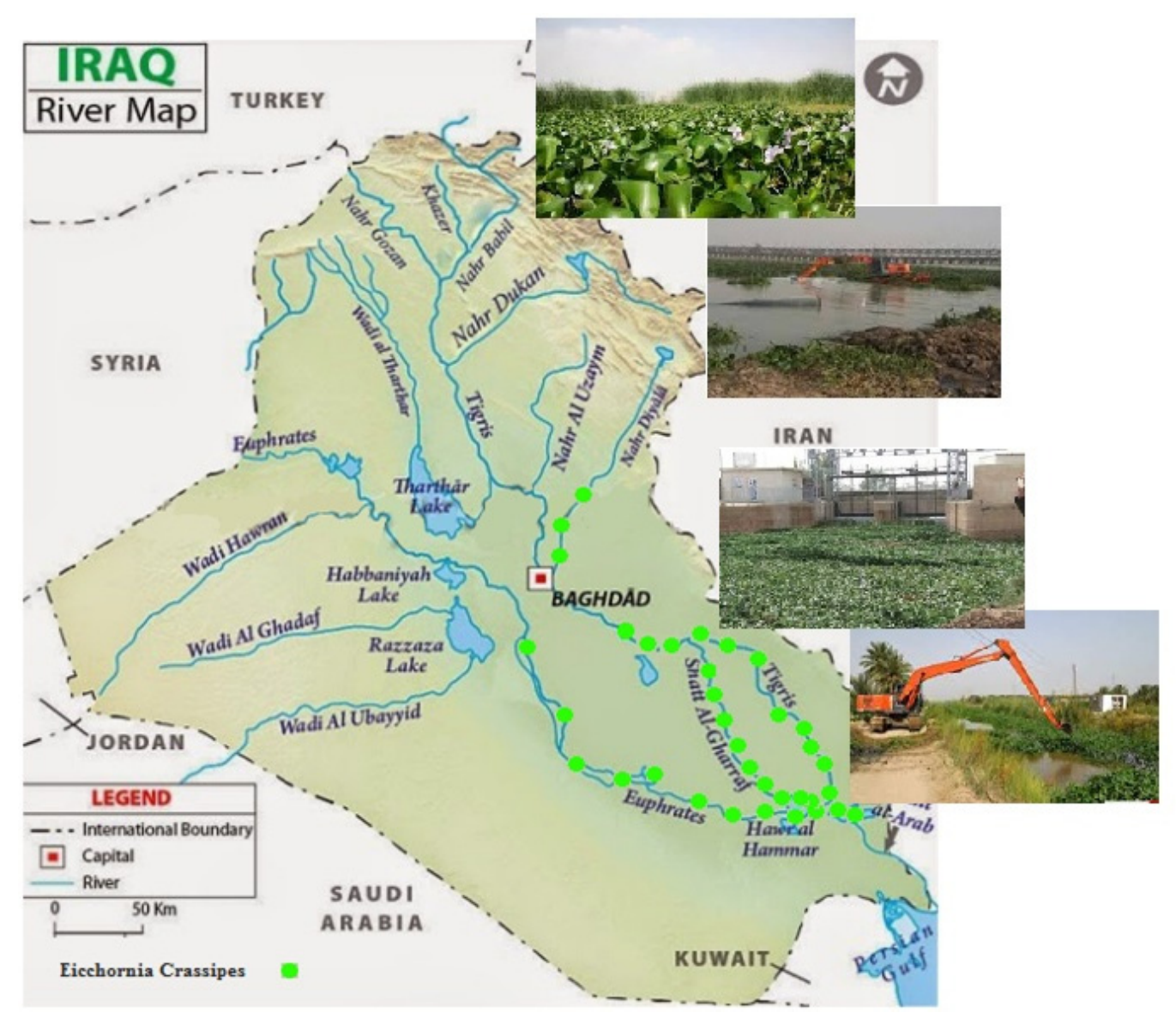

Figure 1. Distribution of E. crassipes in Iraqi rivers.

The growth of E. crassipes plants in Iraqi water streams and rivers represents a severe problem to the health, fishery, and agriculture industries in Iraq. The massive growth of $E$. crassipes plants affects the environment and various socioeconomic factors in Iraq. Unfortunately, this harsh plant is not utilized by any means in Iraq and the Middle Eastern region.

As for the sustainability and supply chain, the areas rich with E. crassipes with massive scale availability are shown as green dots in Figure 1. These are concentrated in the southern and eastern parts of Iraq. The process and optimization of the exhaustive supply chain could be assimilated utilizing the model proposed by [18].

\subsection{Motivation and Research Objective}

The aggressive growth of the E. crassipes plant causes severe environmental and socioeconomic problems in Iraq. This plant represents a strong promise in the biofuel industry due to its fast growth with no human nursing or attention. Hence, the motivation of the current research is to assess the validity of the potential use of extracted biodiesel from E. crassipes as added biofuel to the neat diesel produced in Iraqi refineries. This research is the first attempt to produce biodiesel from the E. crassipes plant in Iraq and assess its technical and environmental characteristics. In addition to pure diesel, three mixed blends were prepared and subjected to characterization and evaluation as fuel for internal combustion (IC) engines. Each mixture consisted of neat diesel (D) and 10\%, 20\%, and $40 \%$ by volume of biofuel blended with $E$. crassipes. Investigation results are presented as fuel blend characteristics, engine performance at various operational conditions, and exhaust gas analysis to assess the environmental impact. 


\section{Materials and Methods}

\subsection{Biodiesel Production Procedure}

In the current investigations, biofuel ethanol was produced in two steps: saccharification and fermentation. The stationary fermentation method was adopted. For saccharification, intact fungal organism Aspergillums Niger was used as a source of cellulose enzyme. The plant is shown in Figure 2.

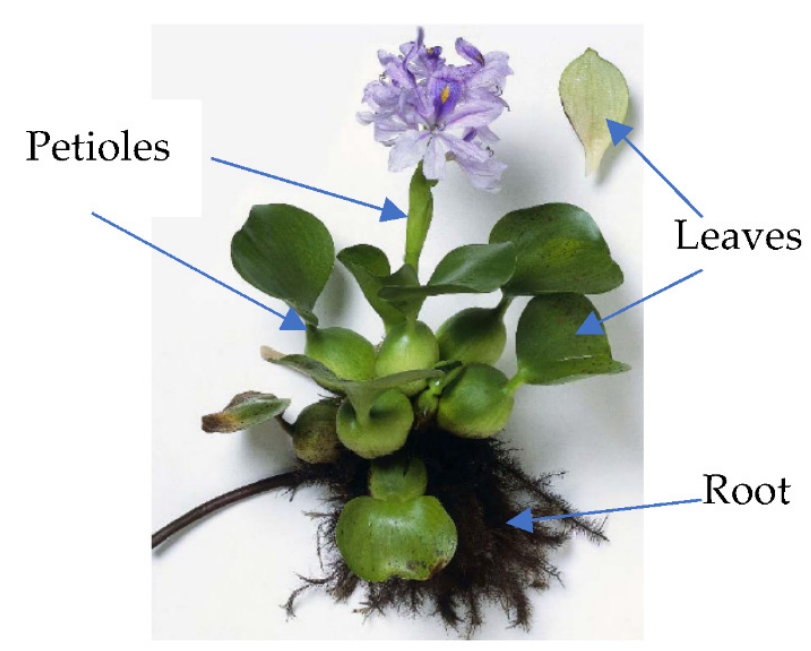

Figure 2. A single plant of Eichhornia crassipes (water hyacinth) extracted from a harvested batch from Dhi-Qar marsh-Iraq.

Leaves, petioles, and roots were separated from the E. crassipes plant. The roots were discarded because they absorb heavy metal pollutants from water. The leaves and petioles were washed manually with tap water and distilled water to remove any solid particles. Subsequently, they were sundried and pre-treated with $1.0 \% \mathrm{NaOH}$ for two hours. About $30 \mathrm{~kg}$ was brought from the site to the University of Technology for characterizations and testing.

To characterize the bio composition of the plant, the following procedure has been followed [19]:

- A small amount of the stems and leaves were taken to the chemical department laboratory for bio composition characterization. The small amount was rinsed with distilled water and left to dry at room temperature. The sample was further dried in an electric oven at $110^{\circ} \mathrm{C}$ for a day to remove the moisture.

- The dry sample was ground into powder using a grinding mill, and the particles were sieved using a $300 \mu \mathrm{m}$ standard sieve.

- A sample of $100 \mathrm{~g}$ of the powder was tested by Fourier transform infrared spectroscopy (FTIR) machine. The wavelength resultant was compared to a standard chart to identify the percentage of cellulose, hemicellulose, and lignin.

The test results are shown in Table 1.

Table 1. Components of Eichhornia crassipes (Water Hyacinth).

\begin{tabular}{cc}
\hline Components & Values in g per 100 g Dry Matter \\
\hline Hemicellulose & 28.87 \\
Cellulose & 32.56 \\
Lignin & 4.16 \\
\hline
\end{tabular}

To blend the diesel from the $30 \mathrm{~kg}$ of E. crassipes, $6.0 \mathrm{wt} . \%$ sulfuric acid catalyst and a methanol-to-oil ratio of 5:1 was processed in a hydrodynamic cavitation reactor at $60^{\circ} \mathrm{C}$ using circulating liquid glycerin for $45 \mathrm{~min}$, as recommended by [17]. A hydrodynamic 
cavitation reactor with $50 \mathrm{~L}$ capacity was used to produce E. crassipes oil biodiesel. The reactor consisted of a diaphragm pump, double-jacked glass, and air compressor to operate the double diaphragm pump, which acted as a device to dissipate the energy in the hydrodynamic cavitation reactor [20-22]. Outlines of the laboratory production of biodiesel from E. crassipes plant are presented in Figure 3.

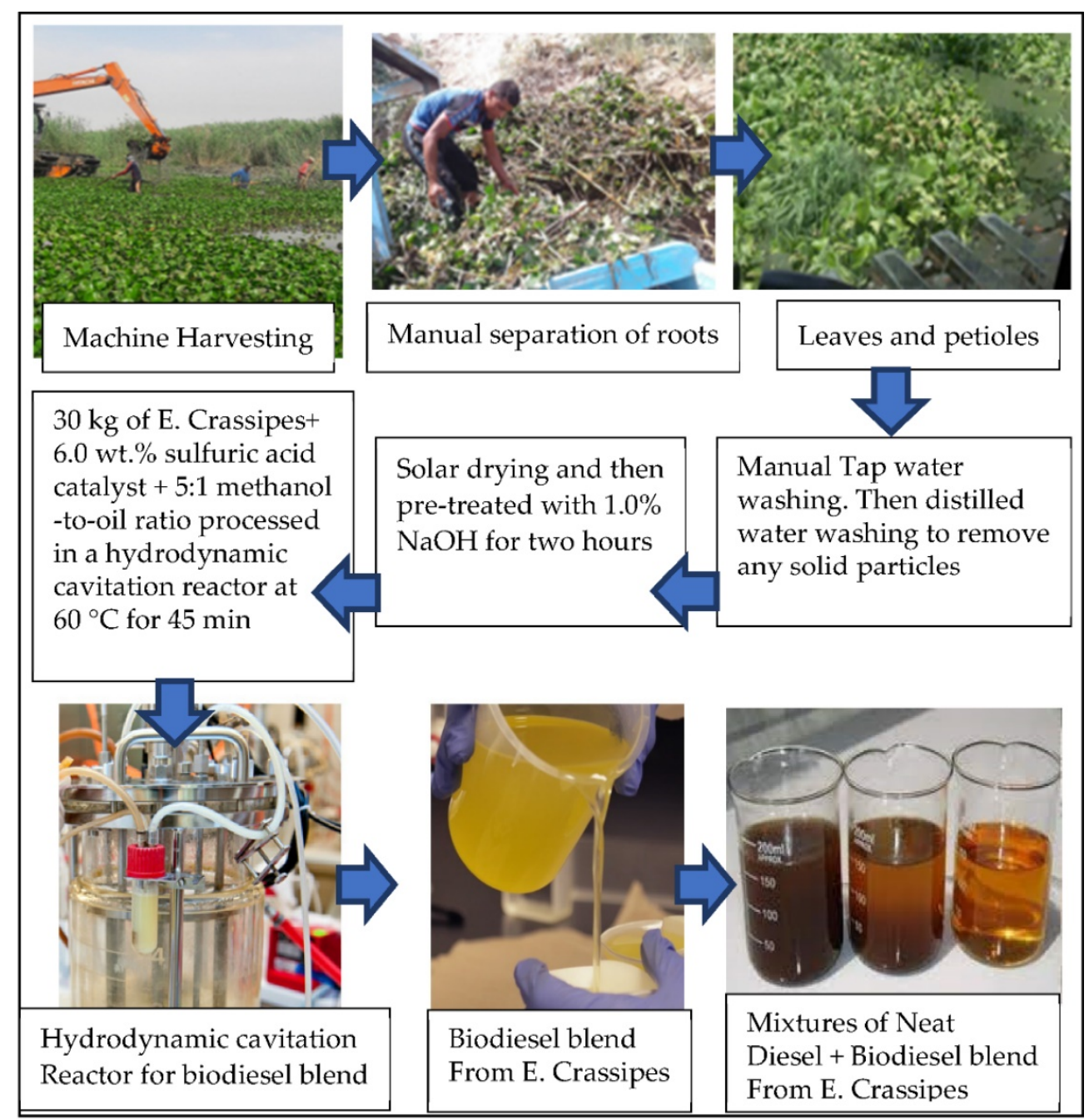

Figure 3. Outlines of the biodiesel blending process of the current investigation.

Mixtures of fuel blends were prepared from diesel and blended biodiesel from $E$. crassipes (BE). The mixture consisted of $90 \% \mathrm{D}$ and $10 \% \mathrm{BE}$ by vol. ( $\mathrm{D}+10 \mathrm{BE})$. The second fuel blend contained $80 \% \mathrm{D}$ and $20 \% \mathrm{BE}$ by vol. $(\mathrm{D}+20 \mathrm{BE})$, and the third fuel blend contained $60 \% \mathrm{D}$ and $40 \% \mathrm{BE}$ by vol. ( $\mathrm{D}+40 \mathrm{BE})$. These samples were subsequently used to fuel the experimental diesel engine setup to measure their performance and emission characteristics.

\subsection{Diesel and Biodiesel Characterization}

The physiochemical properties of the four fuel samples, D, D + 10BE, D + 20BE, and $\mathrm{D}+40 \mathrm{BE}$, were measured following the ASTM and EN standards fuel characterization procedure. The standard procedures followed for the characterization and the equipment, with their accuracies, are as below:

Density: Anton Paar Densometer (model DMA 4500M with a resolution of $0.00001 \mathrm{~g} / \mathrm{cm}^{3}$ and accuracy of $0.000005 \mathrm{~g} / \mathrm{cm}^{3}$ ) was used to measure density following the ASTM D-5002 standard method. 
Viscosity: Anton Paar Lovis rolling ball viscometer (model $2000 \mathrm{M} / \mathrm{ME}$ with viscosity measuring range of $0.3 \mathrm{mPa}$.s to $10,000 \mathrm{mPa} . \mathrm{s}$ and accuracy of up to $0.5 \%$ of the reading) was used to measure viscosity according to the $2000 \mathrm{M} / \mathrm{ME}$ method.

$\bigcirc \quad$ Flashpoint was obtained using a CPP 5Gs analyzer, with an accuracy of $0.1{ }^{\circ} \mathrm{C}$, following the ASTM D-2500 procedure.

- Pour point temperatures were found using a CPP 5G analyzer, with an accuracy of $0.1^{\circ} \mathrm{C}$ following the ASTM D-97 testing procedure.

- Cold filter plugging point was obtained using an FPP 5Gs analyzer, with two infrared detection barriers, following the ASTM D-6371 standard test procedure.

$\bigcirc \quad$ The Oxidation stability was obtained using an 873-CH-9101 Metrohm analyzer, with an accuracy of $0.3^{\circ} \mathrm{C}$, following EN-14112 standard testing procedure.

- The Cetane number was analyzed using SHATOX SX-100K equipment, with 1.0 Cetane level measurement error, following the ASTM D-613 standard method.

$\bigcirc$ Ramé-hart, Model 260, with an accuracy of $\pm 0.10^{\circ}$, was used to measure the surface tension according to the pendant drop method.

- Pregl-Dumas method was adopted to determine the diesel contents of Carbon, Nitrogen, Hydrogen, and Oxygen by CHNS analyzer.

- Gas chromatography with the flame ionization detector has been used to determine the fatty acid components.

Previous researchers discussed in this article's literature, such as [3,5,9,10,12,13,19], have also used the abovementioned standard procedures and equipment.

\subsection{Experimental Setup}

The experimental setup utilized in the current investigations consisted of a diesel engine type TWD290F with a BEA 460 Bosch gas analyzer supplied with specialized software for data acquisition attached to the engine exhaust. The experimental setup is shown schematically in Figure 4. The combustion performance was achieved using a direct injection single-cylinder diesel engine with specifications provided in Table 2.

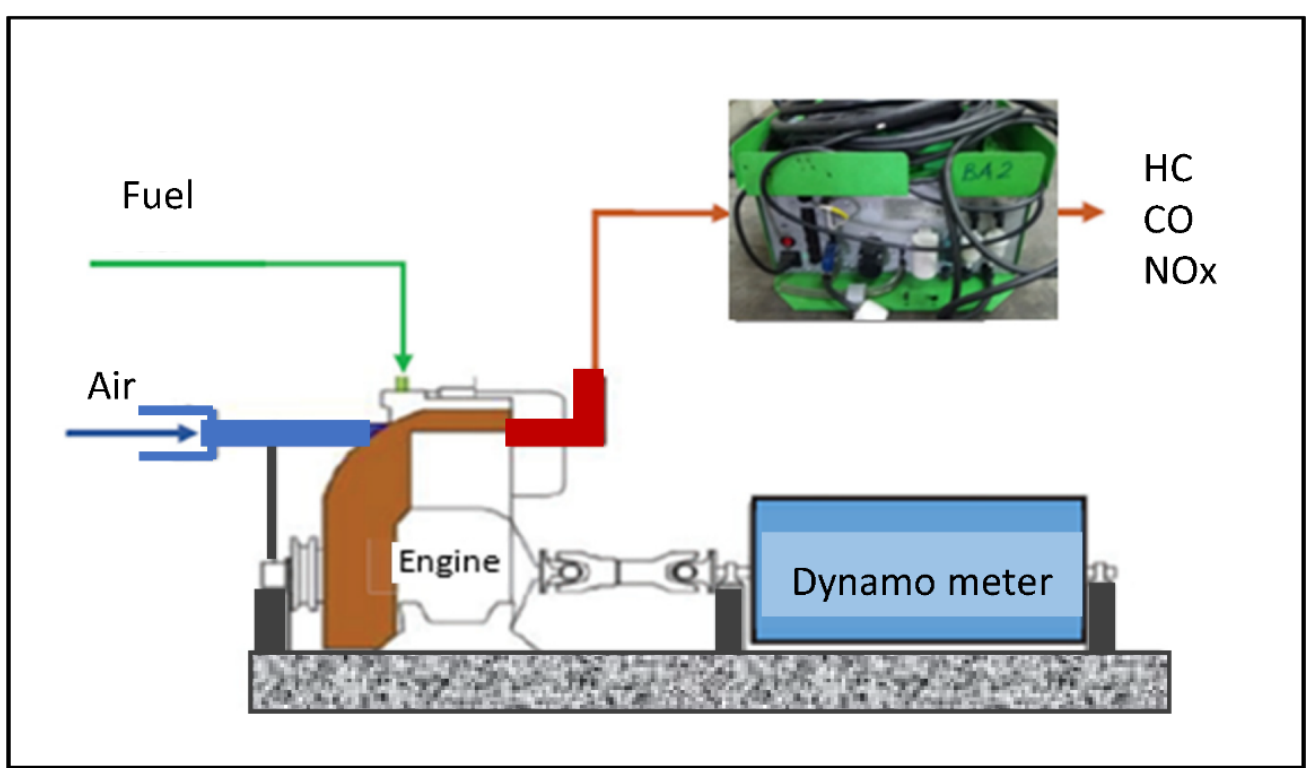

Figure 4. Layout of the experimental setup comprises a four-stroke single cylinder engine type TWD290F, dynamometer, and BEA 460 Bosch gas analyzer. 
Table 2. Test engine specification.

\begin{tabular}{cc}
\hline Parameter & Values \\
\hline No. of cylinders and Strokes & 1 Cylinder; four-stroke \\
Cylinder bore & $85 \mathrm{~mm}$ \\
Stroke & $88 \mathrm{~mm}$ \\
Displacement volume & $653 \mathrm{~cm}^{3}$ \\
Compression ratio & $21.5: 1$ \\
Maximum speed & $3200 \mathrm{RPM}$ \\
Injection timing & $21^{\circ} \mathrm{BTDC}$ \\
\hline
\end{tabular}

The experimental system enables measurement of engine speed, engine torque, fuel flow rate, airflow rate, and all relevant temperatures and pressures. The software automatically optimizes the gas analysis. The experiments were performed at an engine speed of 2000 RPM at different throttling positions (20-100\%). The engine's maximum power is $6.6 \mathrm{~kW}$ at $3200 \mathrm{RPM}$.

Experiment data were recorded after around 4 min of the starting or changing operation status, where the engine reached a stabilized operation status. The measurements were performed at steady-state operational conditions.

\subsection{Uncertainty Analysis}

Error analysis in the experiments is essential to provide a level of confidence in the results. It could be achieved by determining the repeatability and reproductivity of the results. All experiments were repeated thrice. The variants of the predicted values of performance factors and exhaust emissions were used to calculate the uncertainty using the percent relative standard error, $\varnothing$, as shown in Equation (1):

$$
\varnothing \%=\left(\frac{S E}{Y}\right) \times 100,
$$

where $S E$ is the standard error, and $Y$ is the mean of the collected data. The standard error is calculated using Equation (2):

$$
S E=\frac{\sigma}{\sqrt{k}}
$$

where $\sigma$ is the standard deviation, and $k$ is the repeatable readings of performance, combustion characteristics, and emission parameters.

Overall experimental uncertainty, $\sigma_{n}$, was calculated using Equation (3):

$$
\sigma_{n}=\sqrt{\sigma_{1}^{2}+\sigma_{2}^{2}+\ldots+\sigma_{i}^{2}}
$$

where $\sigma_{n}$ is the total uncertainty, and $\sigma_{1}, \sigma_{2}$, and $\sigma_{i}$ are the uncertainties of the individual parameters.

The accuracies and uncertainties of the measured parameters are given in Table 3.

Table 3. Uncertainties of the measured parameters.

\begin{tabular}{cccc}
\hline Parameters & Maximum Value Limit & Accuracy & Uncertainty \\
\hline Speed $(\mathrm{rpm})$ & 6500 & $\pm 1 \mathrm{rpm}$ & \pm 1.75 \\
Torque $(\mathrm{N} \cdot \mathrm{m})$ & 450 & $\pm 0.2 \mathrm{~N} \cdot \mathrm{m}$ & \pm 0.77 \\
BSFC $(\mathrm{g} / \mathrm{kW} \cdot \mathrm{h})$ & - & $\pm 2.12 \mathrm{~g} / \mathrm{kW} \cdot \mathrm{h}$ & \pm 0.89 \\
CO $(\mathrm{vol} . \%)$ & $20 \%$ & $\pm 0.02 \mathrm{vol} \%$ & \pm 1.56 \\
NOx $(\mathrm{ppm})$ & $10,000 \mathrm{ppm}$ & $\pm 2 \mathrm{ppm}$ & \pm 3.21 \\
HC $(\mathrm{ppm})$ & $5000 \mathrm{ppm}$ & $\pm 2 \mathrm{ppm}$ & \pm 1.85 \\
\hline
\end{tabular}




\section{Thermodynamic Analysis}

Thermodynamic analyses were carried out for a full load (engine throttle positioned at $100 \%$ ) at maximum power, which the engine presents at 2000 RPM. Energy and exergy analyses were used, and the first and second law efficiencies were obtained. The overall engine was assumed to be a control volume with a steady-state open system, as shown in Figure 5. In this analysis, air and fuel charges were entered into the engine, and exhaust gas charges exited from the system boundary after losing heat and work. The inlet air and exhaust gases were acceptably presumed as ideal gases. The environmental conditions were considered as $1 \mathrm{~atm}$ and $25^{\circ} \mathrm{C}$. The kinetic and potential energy were neglected for fuel, air, and exhaust.

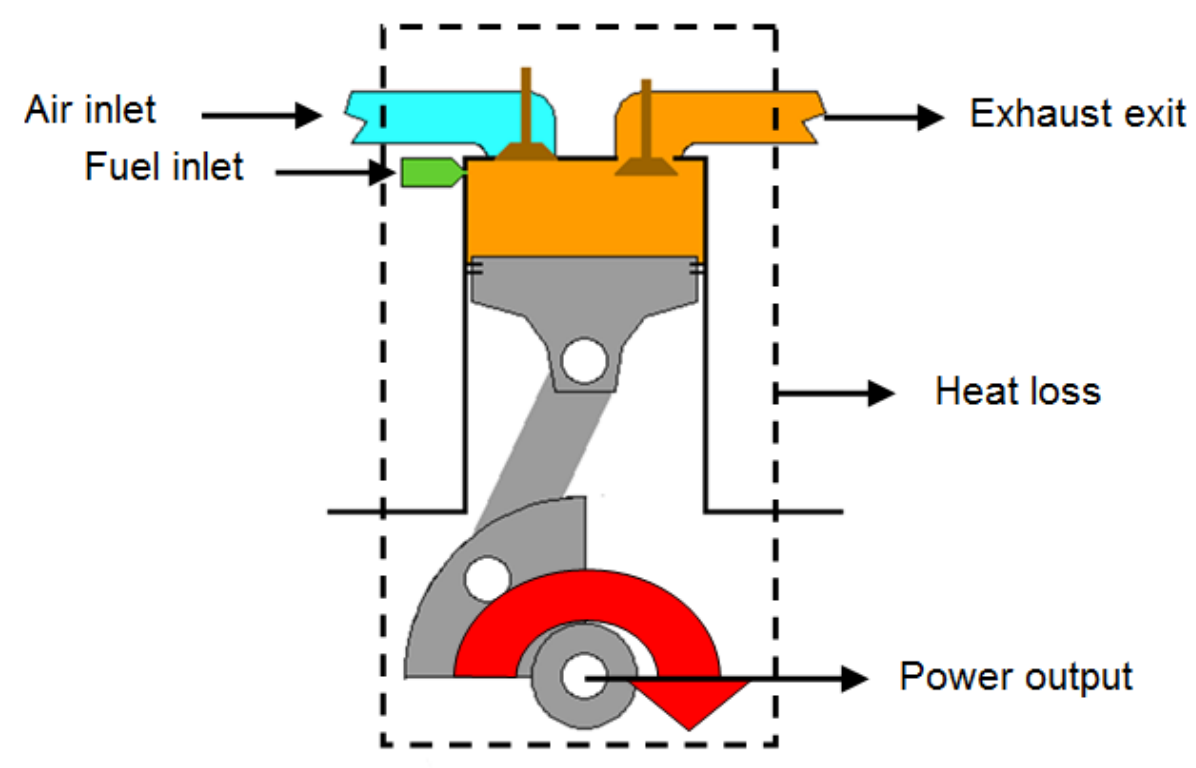

Figure 5. Schematic of the thermodynamic open system.

The molar rate and fractions were estimated from the combustion equation. Fuel and airflow rates were measured experimentally, and the emissions, including $\mathrm{CO}_{2}, \mathrm{CO}$, $\mathrm{NO}$, and $\mathrm{HC}$, were known. Hence, the residual species' molar rates could be determined. Consequently, all molar rates could be placed in the combustion equation. $\mathrm{NO}_{2}$ was not observed in the emissions, and PM has been neglected since they were sufficiently low [23].

$$
a\left(\mathrm{C}_{n} \mathrm{H}_{m} \mathrm{O}_{x}\right)+b\left(\mathrm{O}_{2}+3.76 \mathrm{~N}_{2}\right) \stackrel{\Delta}{\rightarrow} c \mathrm{CO}+d \mathrm{CO}_{2}+e \mathrm{H}_{2} \mathrm{O}+f \mathrm{NO}+g \mathrm{HC}
$$

The thermomechanical and chemical exergy of the air and fuel were ignored at the inlet because fuel and air enter the control volume as reference state conditions. Therefore, only the chemical exergy factor $\varnothing$ of fuel was evaluated as follows:

$$
1.0401+0.1728 \frac{x_{1}}{x_{3}}+0.0432 \frac{x_{2}}{x_{3}}+0.2169 \frac{x_{4}}{x_{3}}\left(1-2.0628 \frac{x_{1}}{x_{3}}\right)
$$

Herein, $x_{1}, x_{2}, x_{3}, x_{4}$ are the mass fractions of hydrogen, oxygen, carbon, and sulfur of liquid fuel, respectively. The overall chemical exergy of fuel is:

$$
\dot{Q}_{i n}=\dot{m}_{f} \varnothing H_{u}
$$

The power output was taken from experimental results. The power was predicted from the measured torque and speed, using Equation (7):

$$
\dot{W}=\frac{2 \pi N T}{60}
$$


Exhaust energy, $\dot{Q}_{\text {exh }}$, was evaluated from the thermodynamic tables, as per [23], considering each emission gas species' enthalpy values and molar flow rate, as in Equation (8):

$$
\dot{Q}_{\text {exh }}=\dot{m}\left(h_{\text {exh }}-h_{i}\right)
$$

Heat losses exit from control volume is calculated from the difference between the inlet and exit energy. Herein, the air energy was ignored since it enters as reference state temperature:

$$
\dot{Q}_{\text {loss }}=\dot{Q}_{i n}-\dot{W}-\dot{Q}_{\text {exh }}
$$

The exergy of the exhaust gases, $\epsilon_{e x h}$, is the sum of thermomechanical and chemical exergies species. The thermomechanical exergy, $\epsilon_{e x h}$, was evaluated from thermodynamic tables for each species as follows:

$$
\epsilon_{\text {exh }}=\left(h-h_{i}\right)-T_{i}\left(s-s_{i}\right)
$$

The chemical exergy in the exhaust gases, $\epsilon_{\text {chem }}$, was evaluated using standard molar chemical exergy, $\eta_{c h}$ table, Model II by [24] and using molar fractions, $\psi$, as follows:

$$
\epsilon_{\text {chem }}=\sum \psi \cdot \eta_{\text {ch }}+R T_{i} \sum \psi \cdot \ln \psi
$$

The exhaust exergy rate can be defined as the sum of the chemical and the thermomechanical exergy multiplying molar rates:

$$
\dot{E}_{e x h}=\sum \dot{m}\left(\epsilon_{e x h}-\epsilon_{c h e m}\right)
$$

The work exergy rate is equal to the power output:

$$
\dot{E}_{w}=\dot{W}
$$

The heat loss exergy, which consists of friction, radiation, and cooling water losses, etc., was assumed, in actuality, to occur from the $363 \mathrm{~K}$ engine cylinder block to the $298 \mathrm{~K}$ reference environment [25]. The heat loss exergy rate can be defined as:

$$
\dot{E}_{\text {heat }}=\sum\left(1-\frac{T_{i}}{T_{w}}\right) \dot{Q}_{\text {loss }}
$$

The exergy destruction rate is obtained from the exergy balance and the difference between the inlet and outlet exergies as follows:

$$
E_{\text {in }}-E_{\text {out }}=E_{w}^{\cdot}+E_{\text {exh }}^{\cdot}+E_{\text {heat }}
$$

Therefore, the first law efficiency is obtained as the ratio of the power output, $W$, to the fuel energy rate, $Q_{i n}$, in Equation (16):

$$
\eta_{1}=\frac{W}{Q_{i n}}
$$

The second law efficiency, which is referred to as exergetic efficiency, could be estimated using Equation (17):

$$
\eta_{2}=\frac{E_{w}}{E_{\text {in }}}
$$

\section{Results and Discussion}

The acquired data from the experimental measurements were clustered to highlight the effect of the added biodiesel on the pure diesel. One batch of results presents the influence of the added biodiesel on the performance of the IC engine. The second batch of 
results presents the exhaust gas analysis and the emissions, which are important for the environmental consequences.

\subsection{Characterization Results}

The mixtures of neat diesel and biodiesel have been characterized as described in Section 2.2. The properties of diesel and the blends are presented in Table 4. The trend of the characteristic changes with the addition of biodiesel to the neat diesel is similar to the data of [13], but with different values. For example, the measured calorific values for $\mathrm{D}+20 \mathrm{BE}, \mathrm{D}+20 \mathrm{BE}$, and $\mathrm{D}+40 \mathrm{BE}$ are $42.2,41.8$, and 39.4, respectively, while, for the current Iraqi diesel and mixtures, they are $44.82,42.67$, and 42.15 . This difference in the calorific values showed some differences in the other characters between the two studies.

Table 4. Measured properties of fuel blends.

\begin{tabular}{ccccc}
\hline Property & D & D + 10BE & D + 20BE & D + 40BE \\
\hline Density $\left(\mathrm{kg} / \mathrm{m}^{3}\right)$ & 823 & 834 & 847 & 859 \\
Kinematic viscosity at $33{ }^{\circ} \mathrm{C}$ & 4.32 & 4.38 & 4.46 & 4.51 \\
$\left(10^{-6} \mathrm{~m}^{2} / \mathrm{s}\right)$ & 45.3 & 44.82 & 42.67 & 42.15 \\
Calorific value $(\mathrm{MJ} / \mathrm{kg})$ & 52.5 & 73.1 & 94.3 & 107.5 \\
Flash point $\left({ }^{\circ} \mathrm{C}\right)$ & -7.6 & -8.5 & -9.2 & -10.3 \\
Pour point $\left({ }^{\circ} \mathrm{C}\right)$ & 47 & 49 & 51 & 54 \\
Cetane number & 104.3 & 93.11 & 80.2 & 47.3 \\
Oxidation stability $(\mathrm{h})$ & & & & \\
\hline
\end{tabular}

\subsection{Heat Release Rate}

The gross amount of heat release rate (HRR) is the sum of the heat transfer to the chamber of the cylinder and the net heat transfer. The estimation accuracy of the HRR depends on many factors such as the accurate measurement of the in-cylinder pressure, the accurate determination of the TDC location, and the assumptions adopted in the HRR prediction model. The heat release model proposed by Krieger and Borman [26] is adopted in the current investigation. Specific heat ratios are considered as constant at 1.35.

Figure 6 presents the measured heat release rates under different fuel mixtures at various crank angles at maximum power. The combustion start timing could not be determined precisely as all results are taken in $720^{\circ} \mathrm{CA}$. However, it can be said that more fuel ignited at the beginning of the combustion for $\mathrm{D}+40 \mathrm{BE}$, and the ignition delay is longer for D + 10BE compared to neat diesel fuel. A higher Cetane number is found in $\mathrm{D}+40 \mathrm{BE}$, and a high viscosity and density are dominant for $\mathrm{D}+10 \mathrm{BE}$, corresponding with engine geometry.

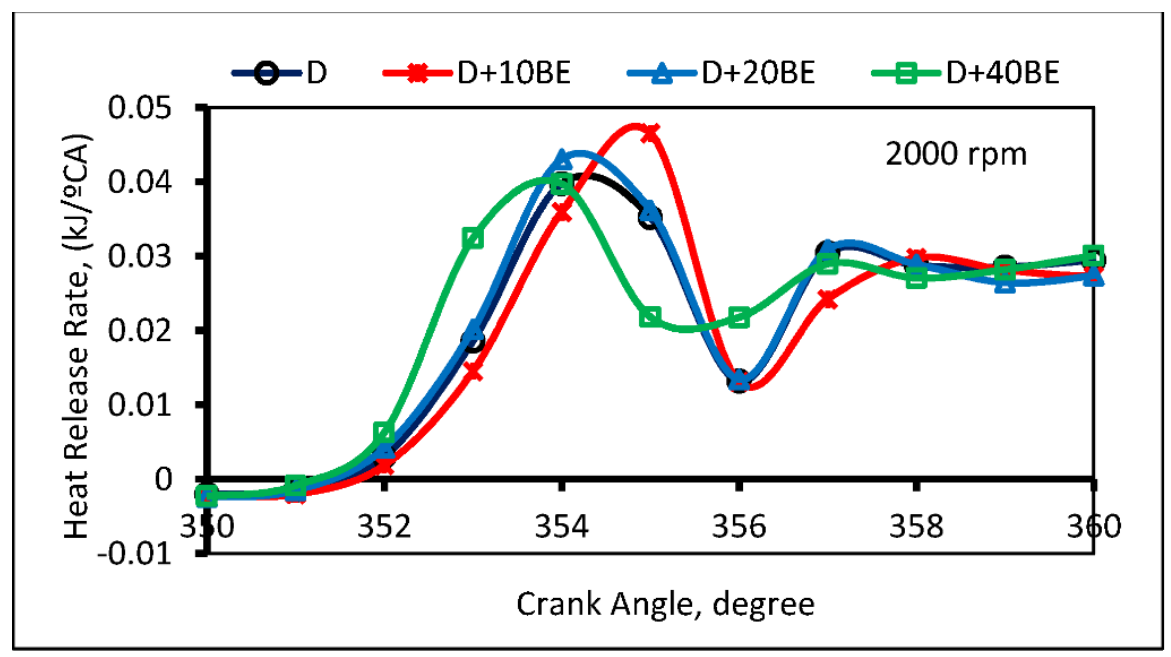

Figure 6. Variation of heat release rate under different fuels at 2000 RPM. 
Moreover, the results presented in Figure 4 display the peak heat release rates. The maximum heat release rate is reached by suddenly burning $\mathrm{D}+10 \mathrm{BE}$, which is waiting before ignition. The test engine produces its maximum torque at $2000 \mathrm{rpm}$. The cases of diesel-biodiesel experimented by [13] have shown lower HRR than pure diesel.

\subsection{Cylinder Pressure}

Figure 7 shows the in-cylinder maximum pressure results. Later ignition causes lower pressure due to expansion and cooling for $\mathrm{D}+10 \mathrm{BE}$. The $\mathrm{D}+40 \mathrm{BE}$ fuel blend has nearly higher peak pressures than pure diesel fuel except at high engine rotational speeds, 2700 and $3000 \mathrm{rpm}$, as the reason mentioned above. The cetane number dominates, and early ignition increases the pressure with a higher Cetane number. D + 20BE generally has similar results with pure diesel fuel.

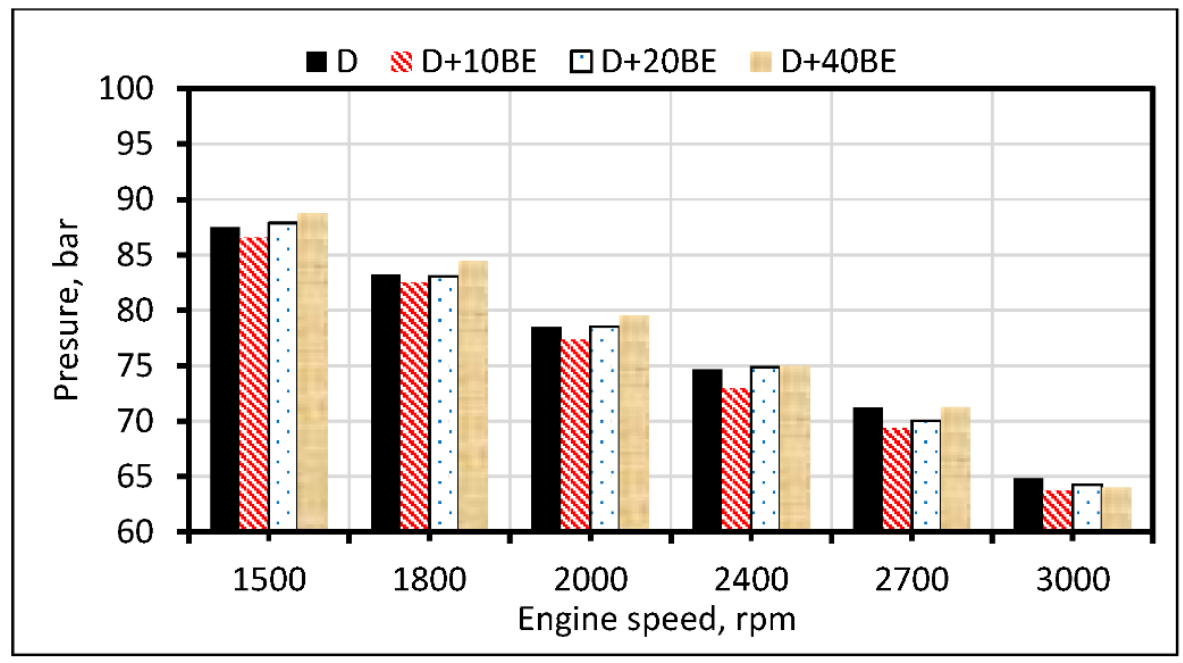

Figure 7. In-cylinder pressure peak values under different engine speeds.

\subsection{Brake Thermal Efficiency}

The brake thermal efficiency (BTE) has been adopted as a performance indicator. The variation of $\mathrm{BTE}$, for the four fuel samples with their blends, $\mathrm{D}, \mathrm{D}+10 \mathrm{BE}, \mathrm{D}+20 \mathrm{BE}$, and $\mathrm{D}+40 \mathrm{BE}$, at varying loading conditions is presented in Figure 8 . The break efficiency of $\mathrm{D}$, $\mathrm{D}+10 \mathrm{BE}, \mathrm{D}+20 \mathrm{BE}$, and $\mathrm{D}+40 \mathrm{BE}$ fuels increases with the load by up to approximately $90 \%$ loading condition, and then begins to decrease.

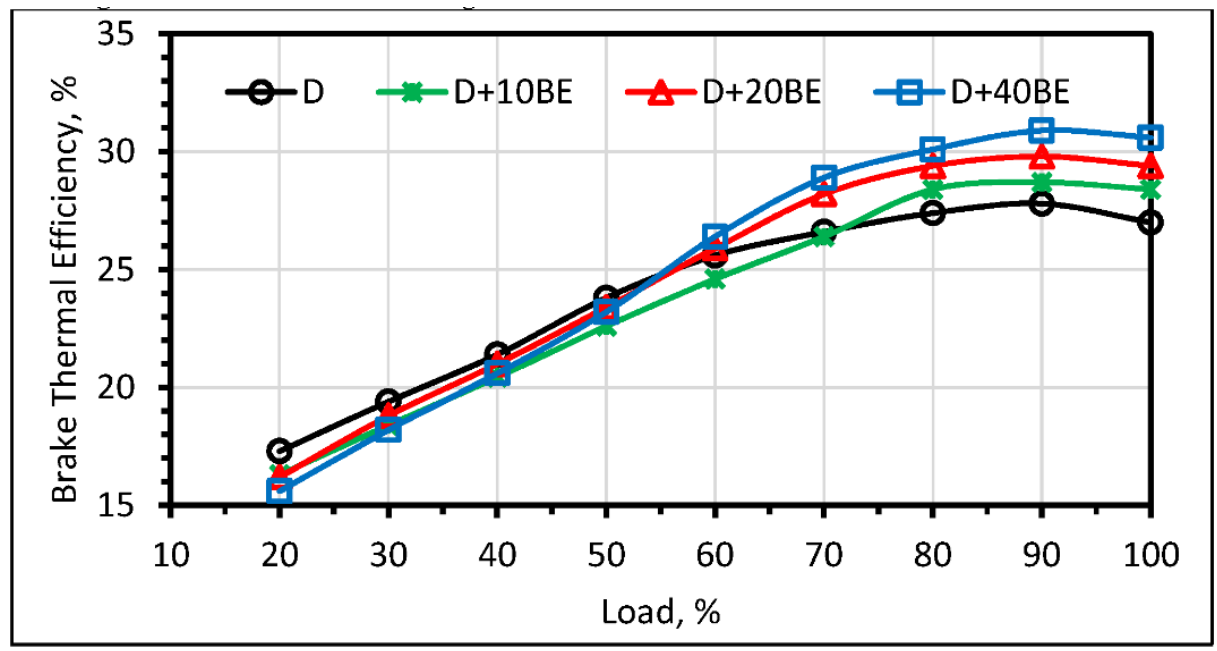

Figure 8. Variation of BTE for all fuel blend samples at various engine loads. 
At high loading conditions, the D $+40 \mathrm{BE}$ blend shows the highest BTE among all other samples since the increase in the biodiesel ratio reduces the volumetric heating value of the blend, thereby causing a decrease in brake power. In addition, the high density and viscosity have resulted in uneven combustion, reducing the brake power [25].

\subsection{Brake-Specific Fuel Consumption}

Figure 9 shows the BSFC changing trend at various engine loads. The BSFC decreased with the increase in engine load for all of the tested fuel samples, thereby demonstrating good combustion. The D + 10BE, D + 20BE, and D + 40BE fuel blends exhibited higher fuel consumption than diesel at all loading conditions. The increase in the BSFC resulted from the low heating value and the high viscosity and density, thereby causing a greater amount of fuel to be injected into the combustion chamber than the D fuel [25]. These results are consistent with the findings of [26-28].

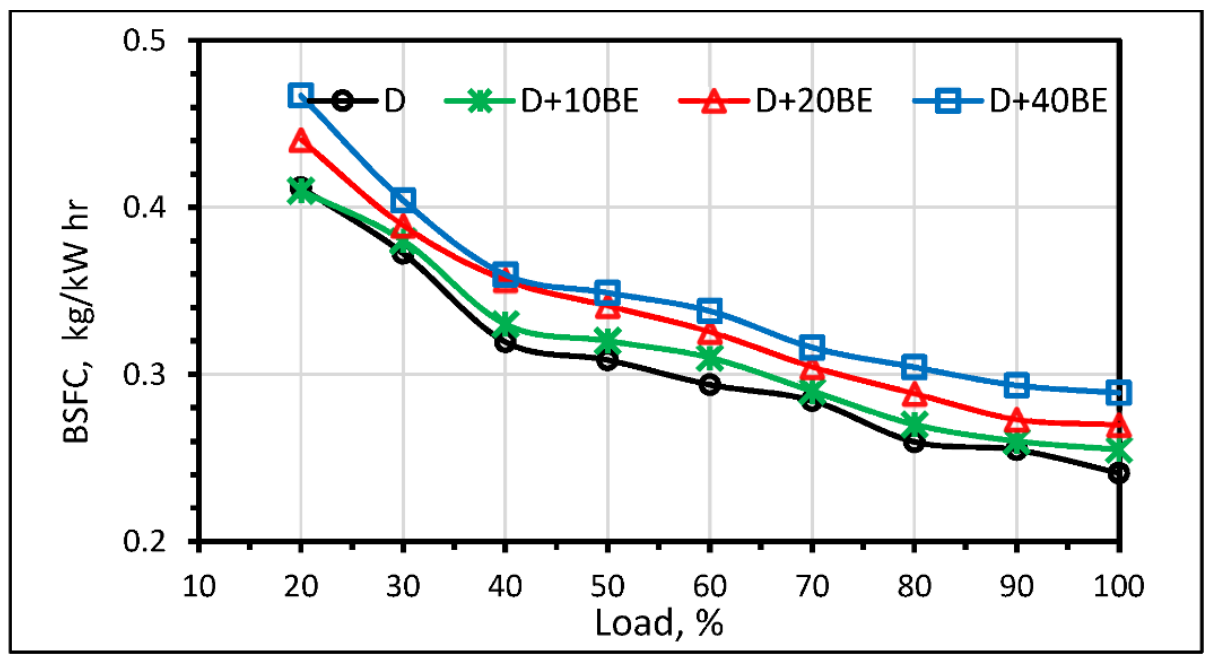

Figure 9. BSFC variation for all fuel blend samples at various engine loads.

\subsection{Environmental Assessment Results}

The consequences of adding biodiesel to the neat diesel changes the chemical composition of the mixture. Hence, the exhaust gases are changing in terms of emission. The resulting $\mathrm{HC}, \mathrm{CO}$, and $\mathrm{NOx}$ have been measured to evaluate the emission characteristics. All of the characterization parameters have been evaluated at different loading conditions of the test engine, varying from a $20 \%$ load to a $100 \%$ full load.

Figure 10 displays the $\mathrm{CO}$ emission of neat diesel and a mixture of diesel and bio blends at various engine loads. Results show that the $\mathrm{CO}$ emissions increase with the engine load because CO emissions are extremely dependent on the air-fuel ratio [13,17]. In addition, the results revealed that $\mathrm{CO}$ emission is the highest in neat diesel, followed by $\mathrm{D}+10 \mathrm{BE}, \mathrm{D}+20 \mathrm{BE}$, and $\mathrm{D}+40 \mathrm{BE}$ fuel blends in all cases of the loading conditions. This effect is evident during full loading conditions but is not so vital at low loads because of their low values. The decrease in CO emissions for the D + 10BE, D + 20BE, and D + 40BE fuel blends may be attributed to the added oxygen percentage in the fuel blend, thereby confirming the remarkable combustion of the fuel. Refs. [12-14] also claimed similar results of slight reductions of $\mathrm{CO}$ percentages in the exhaust gasses of their testing engines using the various percentages of diesel with E. crassipes blends. As experienced by [13], the current investigation demonstrates that the $\mathrm{CO}$ of diesel fuel is higher than the mixtures of diesel with biodiesel at all engine loadings. This is due to oxygen deficiency in diesel fuel overriding the mixtures which have intrinsic fuel oxygen content. The presence of $\mathrm{O}_{2}$ in the fuel enhances the combustion rate and encourages the faster switch of $\mathrm{CO}$ to $\mathrm{CO}_{2}$. 


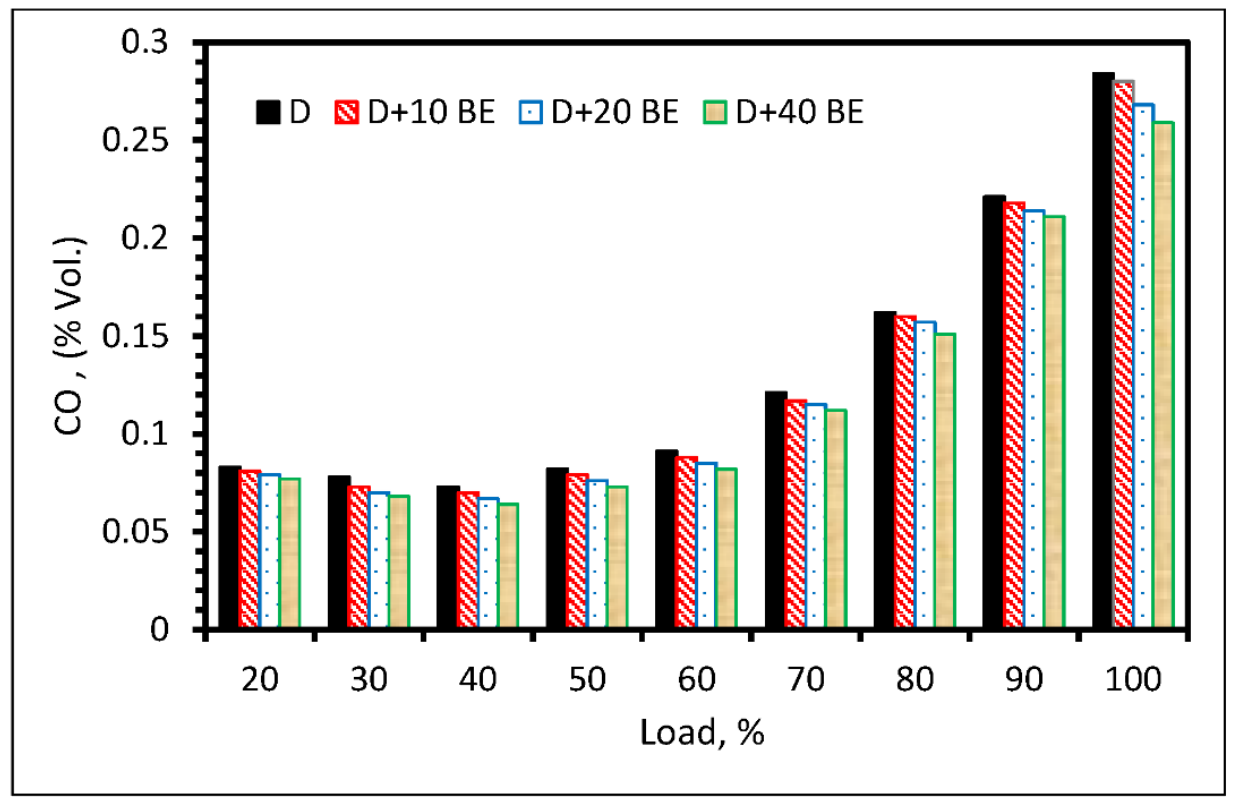

Figure 10. The variant of $\mathrm{CO}$ emission for tested fuel blend samples at various engine loads.

The variation of NOx emission at various engine loads of the considered fuel blends is shown in Figure 11. The engine load increased with the increase in NOx emission. However, the values of the NOx emissions for D + 10BE, D + 20BE, and D + 40BE are above that of pure diesel. Khan et al. [12] also observed slightly higher NOx.

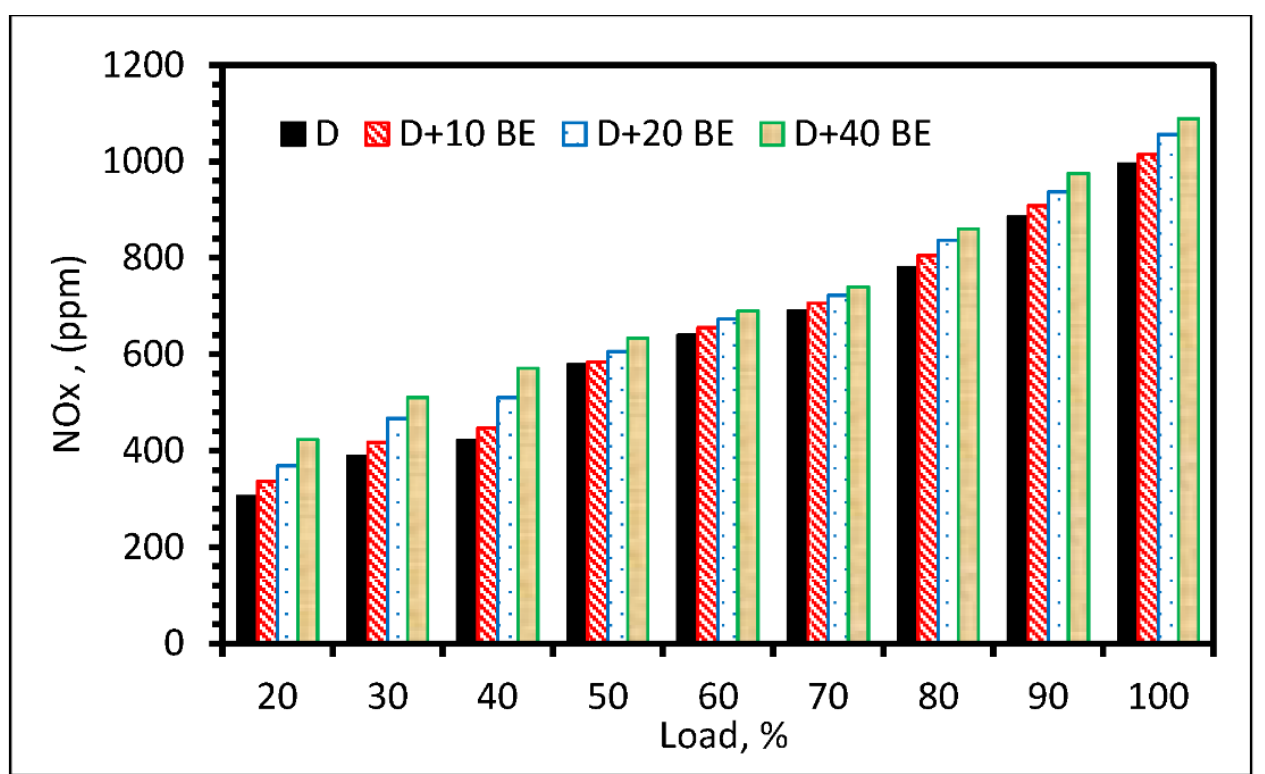

Figure 11. The variant of NOx emission for the tested fuel blend samples for various engine loads.

$\mathrm{HC}$ emission at various engine loads for the studied fuel blends is presented in Figure 12. The $\mathrm{HC}$ emission changes are similar to the $\mathrm{CO}$ emission. Thus, $\mathrm{HC}$ emission is the highest for diesel and lessens for the fuels D + 10BE, D + 20BE, and D + 40BE fuel blends. The reasons for such comportment of $\mathrm{HC}$ emission are described in $\mathrm{CO}$ emission. The low carbon-to-hydrogen ratio and oxygen component in biodiesel fuels have caused improved combustion, reducing HC emissions [29,30]. 


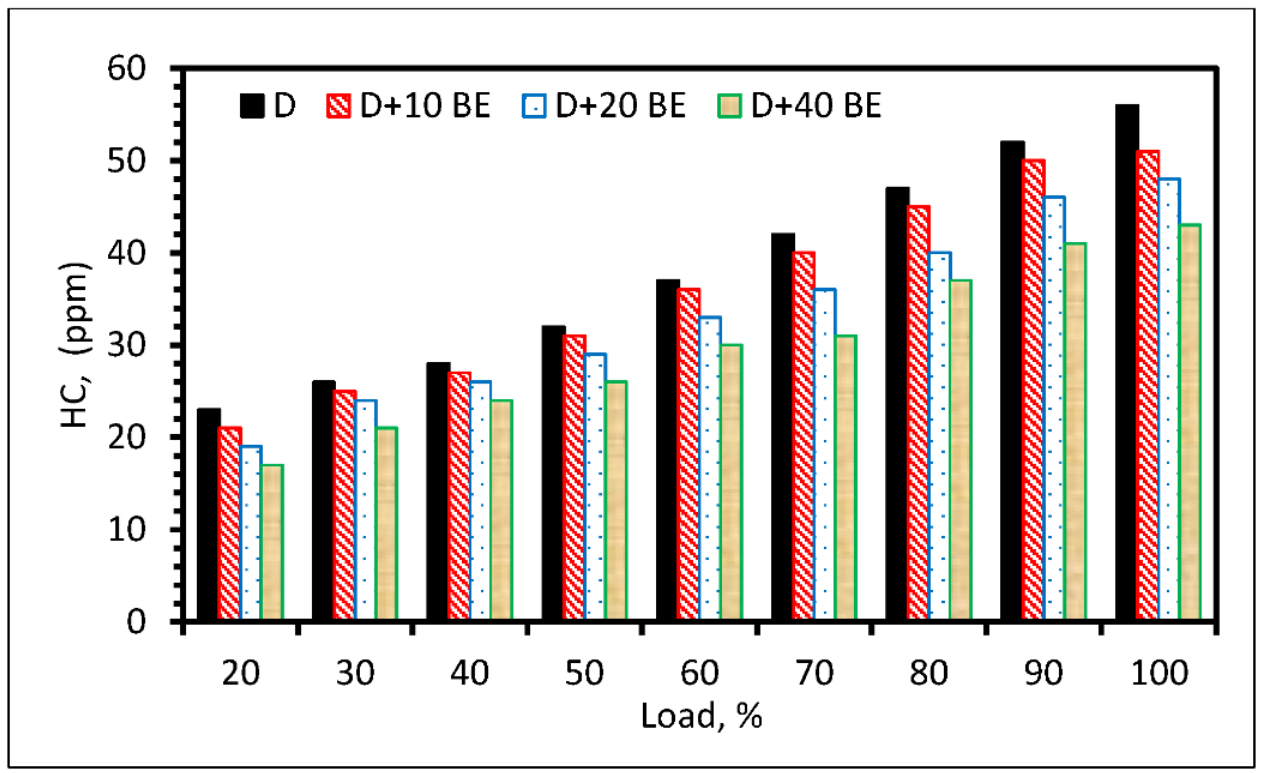

Figure 12. The variant of $\mathrm{HC}$ emission for all fuel blend samples for various engine loads.

\section{Conclusions}

The current research aims to assess the suitability of blended biofuel from E. crassipes plant as an additive to neat diesel in Iraq. The combustion performance and emissions characteristics of biofuel produced from the E. Crassipes plant, and their biodiesel blends have been investigated and compared with neat diesel as baseline fuels. The physicochemical properties of all the considered fuel samples (e.g., D, D + 10BE, D + 20BE, and D + 40BE) are measured according to the ASTM standards. The following conclusions are drawn based on the obtained results:

- $\quad$ Fuel properties: The density and viscosity of the fuel blend increase, and the calorific value decreases with the addition of biofuel.

- $\quad$ The engine performance of IC has been enhanced with the addition of E. crassipes biofuel. Compared with the neat diesel, the biodiesel blend of D + 10BE, D + 20BE, and $\mathrm{D}+40 \mathrm{BE}$ enhanced brake thermal efficiency by $2.6 \%, 4.2 \%$, and $6.3 \%$, respectively.

- The reduction percentage of $\mathrm{CO}$ is $0.85-3.69 \%$ and $2.48-6.93 \%$ of HC compared with the neat diesel. The increasing percentage of NOx compared with pure diesel is 1.87 to $7.83 \%$.

- The assessment results of $40 \%$ biofuel extracted from the E. crassipes and mixed with neat diesel demonstrate a remarkable effect on the engine performance with reduced emission.

The results encourage using the E. crassipes biodiesel blend as an additive to the commercial diesel in Iraq as a potential application. In addition, it resolves the problem of dealing with these plants, as the current practice is to dry the harvested plants under open solar drying. This practice would never eliminate the problem as the seeds survive and grow on a larger scale. Further investigations using different types and amounts of surfactant added to the diesel fuel and blends are recommended.

Author Contributions: The authors contributed to the research as: H.A.A.W.: conceptualization; data curation; investigation; resources and methodology. H.H.A.-K.: formal analysis; funding acquisition; resourcing; writing - review and editing. All authors have read and agreed to the published version of the manuscript.

Funding: This research was funded by PETRONAS, grant number YUTP_FRG, CS: 015LC0-026.

Institutional Review Board Statement: Not applicable.

Informed Consent Statement: Not applicable. 
Data Availability Statement: The data has not been published or made avaialbe in any site.

Acknowledgments: This work was carried out under MOA for international research collaboration between the University of Technology-Iraq (UOT) and the Universiti Teknologi PETRONASMalaysia (UTP). The authors express their thankful remarks for the logistic and technical support by UOT in using the testing equipment in the Mechanical Engineering Department and the financial support by UTP under research grant YUTP-FRG, CS: 015LC0-026.

Conflicts of Interest: The authors declare no conflict of interest.

$\begin{array}{ll}\text { Abbreviations } \\ \text { bTDC } & \text { Before the Top Dead Centre } \\ \text { BSFC } & \text { Specific Fuel Consumption } \\ \text { E. crassipes } & \text { Eichhornia crassipes } \\ \text { HC } & \text { Hydrocarbon } \\ \text { HRR } & \text { heat release rate } \\ \text { PH } & \text { Potential of Hydrogen } \\ \text { ppm } & \text { parts per million }(1 \mathrm{ppm}=1 \mathrm{mg} / \mathrm{L}=1 / 1 \text { million }=0.000001) \\ \text { NOx } & \text { Oxides of Nitrogen }\end{array}$

\section{References}

1. Lam, M.K.; Tan, K.T.; Lee, K.T.; Mohamed, A.R. Malaysian palm oil: Surviving the food versus fuel dispute for a sustainable future. Renew. Sustain. Energy Rev. 2009, 13, 1456-1464. [CrossRef]

2. Abdullah, A.Z.; Salamatinia, B.; Mootabadi, H.; Bhatia, S. Current status and policies on biodiesel industry in Malaysia as the world's leading producer of palm oil. Energy Policy 2009, 37, 5440-5448. [CrossRef]

3. Chuah, L.F.; Azizi, A.R.A.; Yusup, S.; Bokhari, A.; Klemes, J.J.; Abdullah, M.Z. Performance and emission of diesel engine fuelled by waste cooking oil methyl ester derived from palm olein using hydrodynamic cavitation. Clean Technol. Environ. Policy 2015, 17, 2229-2241. [CrossRef]

4. Hirkude, J.B.; Padalkar, A.S. Performance and emission analysis of a compression ignition: Engine operated on waste fried oil methyl esters. Appl. Energy 2012, 90, 68-72. [CrossRef]

5. Hirkude, J.; Padalkar, A.S. Experimental investigation of the effect of compression ratio on performance and emissions of CI engine operated with waste fried oil methyl ester blend. Fuel Process. Technol. 2014, 128, 367-375. [CrossRef]

6. Benjumea, P.; Agudelo, J.; Agudelo, A. Basic properties of palm oil biodiesel-diesel blends. Fuel 2008, 87, 2069-2075. [CrossRef]

7. Math, M.; Kumar, S.P.; Chetty, S.V. Technologies for biodiesel production from used cooking oil-A review. Energy Sust. Dev. 2010, 14, 339-345. [CrossRef]

8. Ramadhas, A.; Muraleedharan, C.; Jayaraj, S. Performance and emission evaluation of a diesel engine fuelled with methyl esters of rubber seed oil. Renew. Energy 2005, 30, 1789-1800. [CrossRef]

9. Sharma, A.K.; Sharma, V.; Sharma, V.; Sharma, J.K.; Singh, R. Multifaceted potential of Eichhornia crassipes (Water Hyacinth) ladened with numerous value aided and therapeutic properties. Plant Arch. 2020, 20, 2059-2065.

10. Rao, K.P.; Reddi, V. Parametric optimization for performance and emissions of DI diesel engine with Mahua biodiesel along with Diethyl ether as an additive. Biofuels 2020, 11,37-47. [CrossRef]

11. Sharma, H.O. Production of biodiesel: Industrial, economic and energy aspects: A review. Plant Arch. 2020, 20, $2058-2066$.

12. Khan, O.; Yadav, A.K.; Khan, M.E.; Parvez, M. Characterization of bioethanol obtained from Eichhornia crassipes plant; its emission and performance analysis on CI engine. Energy Sources Part A Recovery Util. Environ. Eff. 2019, 43, 1793-1803. [CrossRef]

13. Venu, H.; Venkataraman, D.; Purushothaman, P.; Vallapudi, D.R. Eichhornia crassipes biodiesel as a renewable green fuel for diesel engine applications: Performance, combustion, and emission characteristics. Environ. Sci. Pollut. Res. 2019, 26, 18084-18097. [CrossRef]

14. Alagu, K.; Venu, H.; Jayaraman, J.; Raju, V.D.; Subramani, L.; Appavu, P.; Dhanasekar, S. Novel water hyacinth biodiesel as a potential alternative fuel for existing unmodified diesel engine: Performance, combustion and emission characteristics. Energy 2019, 179, 295-305. [CrossRef]

15. Bote, M.A.; Naike, V.R.; Jagadeeshgouda, K.B. Review on water hyacinth weed as a potential bio fuel crop to meet collective energy needs. Mater. Sci. Energy Technol. 2020, 3, 397-406. [CrossRef]

16. Bhattacharya, A.; Kumar, P. Water hyacinth as a potential bio fuel crop. Electron. J. Environ. Agric. Food Chem. 2010, 9, 112-122.

17. Magdum, S.S.; Sandeep, M.M.; Aiyaj, A.N. Biochemical conversion of acid-pretreated water hyacinth (Eichhornia crassipes) to alcohol using Pichia stipites NCIM3497. Int. J. Adv. Biotechnol. Res. 2012, 3, 585-590.

18. Galanopoulos, C.; Giuliano, A.; Barletta, D.; Zondervan, E. An integrated methodology for the economic and environmental assessment of a biorefinery supply chain. Chem. Eng. Res. Des. 2020, 160, 199-215. [CrossRef]

19. Munene, J.M.; Onyatta, J.O.; Yusuf, A.O. Characterization of Water Hyacinth Powder Using FTIR Spectroscopy and the Adsorption Behaviour of $\mathrm{Pb}^{2+}, \mathrm{Cd}^{2+}, \mathrm{Zn}^{2+}, \mathrm{Ni}^{2+}$ and $\mathrm{Cr}^{2+}$ in Aqueous Solution. Asian J. Appl. Chem. Res. 2020, 6, 47-55. [CrossRef] 
20. Agarwal, D.; Agarwal, A.K. Performance and emissions characteristics of Jatropha oil (preheated and blends) in a direct injection compression ignition engine. Appl. Therm. Eng. 2007, 27, 2314-2323. [CrossRef]

21. Bari, S.; Lim, T.; Yu, C. Effects of preheating of crude palm oil (CPO) on injection system, performance and emission of a diesel engine, Renew. Energy 2002, 27, 339-351.

22. Sharma, Y.; Singh, B. Development of biodiesel: Current scenario. Renew. Sustain. Energy Rev. 2009, 13, 1646-1651. [CrossRef]

23. Yüncü, H.; Analizi, E. İkinci Kanun Verimi E Termoekonomik; ODTÜ Basım İşliği: Ankara, Turkey, 2010.

24. Bejan, A.; Tsatsaronis, G.; Moran, M. Thermal Design and Optimization; Wiley-Interscience: Hoboken, NJ, USA, 1996; ISBN 978-0471-58467-4.

25. Tat, M.E. Cetane number effect on the energetic and exergetic efficiency of a diesel engine fuelled with biodiesel. Fuel Process. Technol. 2011, 92, 1311-1321. [CrossRef]

26. Krieger, R.B.; Borman, G.L. The Computation of Apparent Heat Release for Internal Combustion Engines; ASME: New York, NY, USA, $1966 ;$ p. 66.

27. Firestone, D. Official Methods and Recommended Practices of the AOCS; AOCS: Champaign, IL, USA, 2009.

28. El-Kassaby, M.; Nemit-allah, M.A. Studying the effect of compression ratio on an engine fueled with waste oil produced biodiesel/diesel fuel. Alexandria Eng. J. 2013, 52, 1-11. [CrossRef]

29. Rao, G.A.P.; Mohan, P.R. Effect of supercharging on the performance of a DI diesel engine with cotton seed oil. Energy Convers. Manag. 2003, 44, 937-944. [CrossRef]

30. Khalife, E.; Tabatabaei, M.; Demirbas, A.; Aghbashlo, M. Impacts of additives on performance and emission characteristics of diesel engines during steady state operation. Prog. Energy Combust. Sci. 2017, 59, 32-78. [CrossRef] 